\title{
Ectopic brain tissue in the trigeminal nerve presenting as rapid-onset trigeminal neuralgia: case report
}

\author{
Jeffrey H. Zimering, MD, ${ }^{1}$ Jonathan J. Stone, MD, ${ }^{2}$ Audrey Paulzak, MD, ${ }^{2}$ John D. Markman, MD, ${ }^{3}$ \\ Mahlon D. Johnson, MD, PhD, ${ }^{4}$ and G. Edward Vates, MD, PhD ${ }^{2}$ \\ ${ }^{1}$ University of Rochester School of Medicine and Dentistry; ${ }^{2}$ Department of Neurosurgery; ${ }^{3}$ Translational Pain Research Program; \\ and ${ }^{4}$ Department of Pathology, Division of Neuropathology, University of Rochester Medical Center, Rochester, New York
}

\begin{abstract}
The authors report the case of a 52-year-old man who presented with rapid-onset lancinating facial pain consistent with trigeminal neuralgia. Magnetic resonance imaging revealed a nonenhancing small lesion on the right trigeminal nerve concerning for an atypical schwannoma or neuroma. The patient underwent resection of the mass via a right retrosigmoid approach. His facial pain completely resolved immediately postoperatively and had not recurred at 6 months after surgery. The mass was consistent with normal brain tissue (neurons and glial cells) without evidence of mitoses. A final histopathological diagnosis of ectopic brain tissue with neural tissue demonstrating focal, chronic T-cell inflammation was made. The partial rhizotomy during resection was curative for the facial pain. To the authors' knowledge, this is the first report of neuroglial ectopia causing trigeminal neuralgia.
\end{abstract}

https://thejns.org/doi/abs/10.3171/2017.6.JNS17811

KEY WORDS trigeminal neuralgia; neuroglial ectopia; intracranial hamartoma; pain

I NTRACRANIAL glioneuronal hamartoma comprises an exceedingly rare subset of all cerebellopontine angle mass lesions, which can elicit signs and symptoms through cranial nerve involvement. The sudden onset of symptoms due to nerve compression by a small, firm glioneuronal heterotopia has been reported. Yet, to our knowledge, this is the first report of trigeminal neuralgia arising through the presumed compressive effects of a small glioneuronal heterotopia that lacked evidence of vascular co-compression and instead probably involved T-cell-mediated processes.

\section{Case Report}

History and Examination

A 52-year-old man presented to the emergency department with rapid-onset right facial pain. He had experienced severe right-sided headache, stabbing eye pain, photophobia, scotoma, confusion, and tunnel vision for 1 week. The pain was characterized as multiple "stabbing" episodes each day, in the V1/V2 distribution, without a specific trigger. It was not relieved by over-the-counter medications. The patient reported no visual or speech changes, no numbness, tingling, or weakness. He denied any history of falls or trauma. There was no personal or family history of malignancy, or any aneurysm.

His medical history was significant for depression, anxiety disorder, and hypertension (treated with amlo- dipine and hydrochlorothiazide). He was a former smoker (10 pack-years) and drank $15 \mathrm{oz}$ of alcohol per week, but denied intravenous or illicit drug use. Physical examination revealed a well-developed, anxious male: height $6 \mathrm{ft}$, weight $184 \mathrm{lbs}$. Vital signs and physical examination were unremarkable. The neurological examination was normal and without focal findings.

Laboratory tests were remarkable for a serum sodium level of $132 \mathrm{mEq} / \mathrm{L}$, borderline low serum calcium of 8.6 $\mathrm{mg} / \mathrm{dl}$, and normal complete blood count. Magnetic resonance imaging revealed a small, extraaxial, nonenhancing $4 \times 6-\mathrm{mm}$ lesion on the proximal cisternal segment of the trigeminal nerve and nerve root entry zone (Fig. 1). There was no evidence of vascular compression of the nerve on thin-slice $(0.8 \mathrm{~mm})$ FIESTA (fast imaging employing steady-state acquisition) MRI sequences. The lesion was isointense to brain tissue, consistent with atypical schwannoma, neuroma, a small focus of ectopic brain tissue, or a developmental anomaly of the nerve root entry zone. The remainder of the brain parenchyma, brainstem, and cranial nerves appeared normal. The patient was treated with carbamazepine and oxycodone; however, he experienced moderate-to-severe side effects and elected to undergo surgical exploration and resection for a presumed right trigeminal schwannoma.

Operation and Pathological Findings

A right retrosigmoid craniotomy was undertaken for

ABBREVIATIONS GFAP = glial fibrillary acidic protein .

SUBMITTED March 30, 2017. ACCEPTED June 2, 2017.

INCLUDE WHEN CITING Published online December 1, 2017; DOI: 10.3171/2017.6.JNS17811. 
excision of the right trigeminal nerve tumor. After small arachnoidal adhesions were taken down, the right trigeminal nerve was identified and an almond-shaped, firm rubbery mass was found splaying the nerve fibers. The mass appeared to extend from the root entry zone and stopped short of Meckel's cave. Intraoperative frozen sections of the mass revealed that it was abnormal neural tissue without classic schwannoma features. The mass was freed at the distal margin and followed into the dorsal root entry zone. The borders on the proximal margin were unclear; however, it was believed that a gross-total resection was completed. The patient did not experience any postoperative deficits and had normal facial strength and sensation.

Pathological examination revealed normal brain tissue and a right trigeminal neoplasm (Fig. 2A and B). The neural tissue had a focal component of chronic T-cell inflammation evidenced by CD3-immunoreactive $\mathrm{T}$ cells located in and around the trigeminal nerve (Fig. 2C). No CD79a-immunoreactive B cells or CD68 microglia/macrophages were present (not shown). There was no necrosis, axonopathy, or nerve sheath tumor. Immunohistochemical staining was positive for synaptophysin and glial fibrillary acidic protein (GFAP). There were NeuN-immunoreactive neurons (Fig. 2B) and fragments of neurofilaments, and an S100-immunoreactive nerve was present. There was no Ki-67 labeling indicative of mitotic activity.

\section{Postoperative Follow-Up}

The patient experienced complete resolution of his right facial pain in the immediate postoperative period. He was discharged on postoperative Day 1. Two weeks later, he was feeling fine, except for some mild right suboccipital soft-tissue incisional tenderness. Six months after surgery, he had experienced no recurrence of the right facial pain. Physical examination including a neurological exam was normal. The final clinical and pathological diagnosis was ectopic brain tissue in the right trigeminal nerve with focal, chronic T-cell inflammation.

\section{Discussion}

To our knowledge, this is the first report of neuroglial ectopia causing trigeminal neuralgia. The preoperative imaging was consistent with this diagnosis: the lesion was nonenhancing and isointense on T1-weighted images. Neuroglial ectopia can be differentiated from schwannomas, neuromas, or lipomas according to the differences in their MRI signal intensities. ${ }^{22}$ Schwannomas are isointense on T1 noncontrast sequences and homogeneously enhance with gadolinium administration..$^{14}$ In contrast, T1-weighted images without contrast of lipomas and lipomatous hamartomas are hyperintense. ${ }^{15}$ Although the lack of contrast enhancement is a characteristic finding in neuroglial ectopia or gliomatous hamartoma, the rarity of either lesion means that the clinical diagnosis is rarely made preoperatively. ${ }^{3}$

Hamartomas are abnormal collections of nonneoplastic cells in surrounding tissue. ${ }^{1}$ They are believed to arise as a result of abnormal migration and differentiation of cells during embryonic development. Neurogenic hamartomas usually present in the midline as nasal glioma. ${ }^{14}$ Intracranial hamartomas are much less common, accounting for
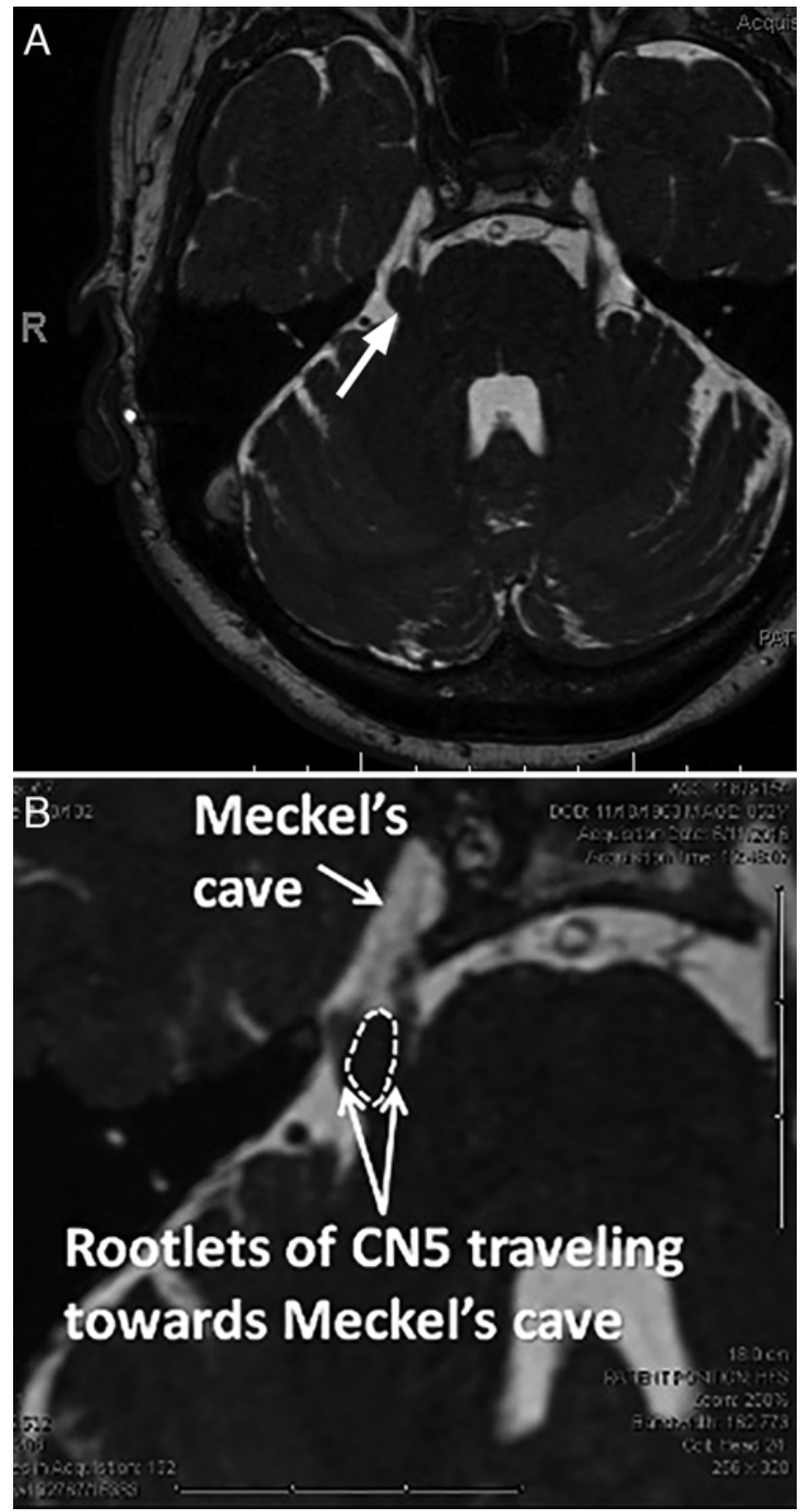

FIG. 1. Brain MR images showing a nonenhancing nodular lesion (arrow, A) isointense to brain tissue along the proximal cisternal segment of the right trigeminal nerve, appearing to project into the nerve root entry zone. The lesion (dotted line, B) partially splays the nerve root fascicles around its margins. CN5 = fifth cranial nerve.

less than $0.2 \%$ of cerebellopontine angle mass lesions, ${ }^{1}$ and consist of lipomatous or glioneuronal types. Intracranial glioneuronal hamartomas have been reported in only 12 cases in the literature, nearly all of which involved the eighth cranial nerve or its branches and presented with hearing loss, vertigo, loss of balance, or tinnitus. ${ }^{1}$ Most of these reports describe the gradual onset of progressive symptoms secondary to infiltrative lesions of the internal auditory canal, ${ }^{6,7}$ however, one case described the sudden onset of hearing loss in a 31-year-old woman with a small, firm, compressive glioneuronal heterotopia. ${ }^{24}$ Cerebellopontine angle tumors are a rare cause of hemifacial 
spasm; in many such cases, tumors displaced the seventh cranial nerve into physical contact with a nearby vessel. ${ }^{8}$ Hamartomas can also occur in the peripheral nervous system, and these typically have a fibrolipomatous histology but a presumed etiopathogenesis different from that of intracranial hamartomas. ${ }^{25}$ Among 26 cases reported in one series, ${ }^{25}$ a small subset caused symptoms of pain (or paresthesias), as in our case.

Immunohistochemical staining of the trigeminal nerve mass - that is, positivity for NeuN, ${ }^{26}$ synaptophysin, and GFAP-confirmed the origin as benign glial and neuronal cells. This suggests that the lesion may have arisen through aberrant migration of primitive neuroectodermal tissue during development. Most cases of trigeminal neuralgia are caused by vascular compression of the trigeminal nerve root ${ }^{17}$ resulting in a loss of central myelination leading to altered conduction. The occurrence of neuroglial ectopia extending from the trigeminal nerve root entry zone in our patient is of interest since this region represents a transitional zone between central and peripheral myelin. ${ }^{9}$ Peripheral myelin is formed by Schwann cells and central myelin by oligodendrocytes. Schwann cell precursors share a developmental origin with neural crest-derived mesenchymal stem cells. ${ }^{12}$ During development, the hematopoietic stem cell niche is thought to be populated (in part) via the perineural spread of such precursor cells. ${ }^{12}$ In contrast, neurons and oligodendrocytes are derived from a common neural stem cell precursor, ${ }^{13}$ suggesting abnormal migration in a pool of neural stem cells, which later differentiate into neurons and glia.

Compression by the ectopic brain nodule may have led to focal demyelination of trigeminal nerve root axons, causing ephaptic conduction perhaps akin to demyelination, which characterizes vascular forms of trigeminal neuralgia and is associated with multiple sclerosis. ${ }^{17}$ While there was no obvious axonopathy on histopathological examination of the lesion, subtle changes in myelin and axon conduction can create spontaneous nerve firing. ${ }^{17}$ The observation of CD3+ T-cell infiltration in a region of histologically near-normal trigeminal nerve suggests a possible immune mechanism for trigeminal neuralgia potentially initiated by the neuroglial heterotopia. T-cell infiltration in the dorsal horn was reported in animal models of mechanically induced or chronic constriction-type peripheral nerve injury. ${ }^{4,18}$ Neuropathic pain in these animal models required the presence of functioning $\mathrm{T}$ cells and was associated with $\mathrm{T}$ cell-mediated cytokine production. ${ }^{4,18}$ In an animal model of multiple sclerosis pain-that is, experimental autoimmune encephalomyelitis-early-stage dorsal horn T-cell infiltration was followed by later-stage microglia/macrophage infiltration..$^{20}$

The absence of immunoreactive CD68 microglia/macrophages in the lesion in our case may be consistent with nerve compression by the glioneural nodule triggering the rapid onset of severe pain (in part) via earlier T cell-mediated processes. In contrast, macrophage infiltration of the trigeminal nerve was previously reported in 3 older patients with refractory trigeminal neuralgia (not due to vascular compression) and a mean duration of symptoms of $4-5$ years. ${ }^{10}$

Intracranial glioneuronal heterotopias are rare congenital lesions that can arise in the head, face, or neck and
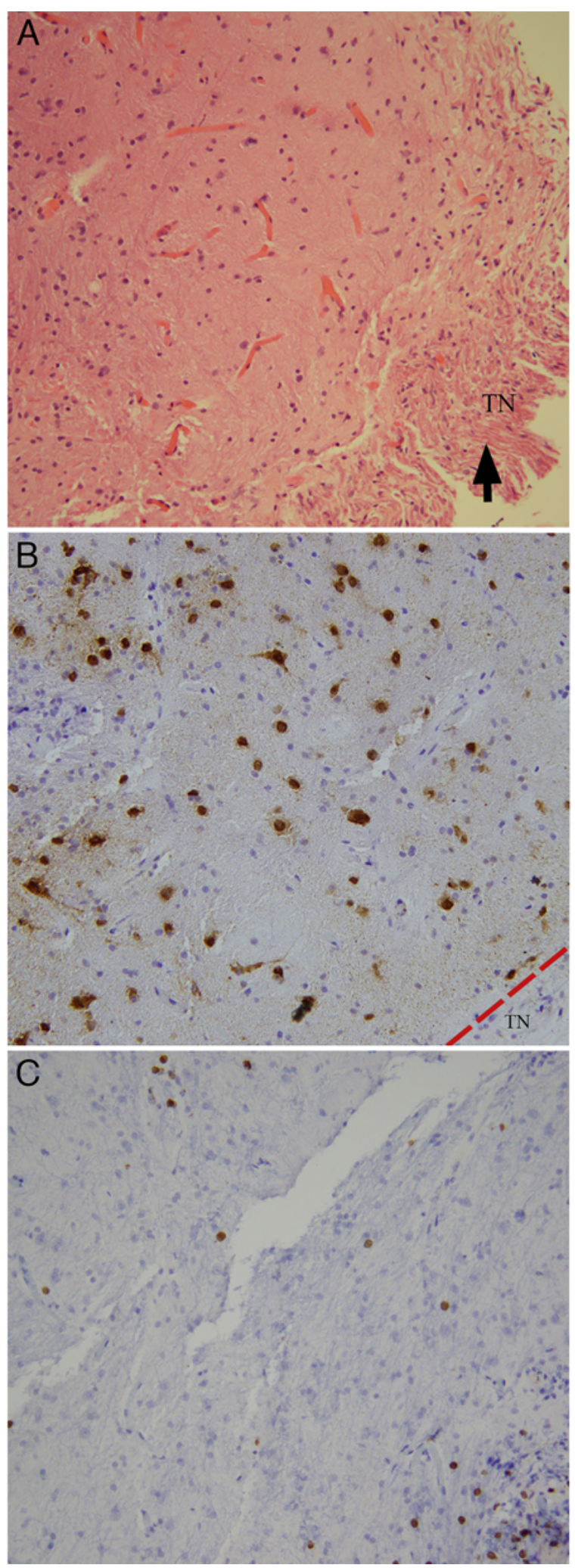

FIG. 2. Histological and immunohistochemical images of the ectopic brain lesion. $H \& E$, original magnification $\times 200$ (A). NeuN immunoreactivity, hematoxylin counterstain, original magnification $\times 200$ (B). CD3 immunoreactivity, hematoxylin and DAB counterstain, original magnification $\times 200(C)$. Arrow (A) and dashed line $(B)$ in the lower right corners indicate the trigeminal nerve (TN) and its boundary with the ectopic brain lesion, respectively. Figure is available in color online only. 
consist of small or large nodular aggregates of neuronal and glial cells. ${ }^{2,11,19,21}$ In a case described by Freeman, ${ }^{5}$ the lesion (comprised of mature neurons and glia) was found in the pontine meninges of a 55-year-old asymptomatic woman at autopsy. This suggests that small brain ectopia or heterotopias can go unrecognized or occur more commonly than previously suspected. In contrast, much more severe forms of intracerebral heterotopia involving abnormal cortical lamination typically present at birth or in the prenatal period and are associated with epilepsy. For example, human bilateral frontoparietal polymicrogyria is caused by a loss-of-function mutation in the adhesion $\mathrm{G}$ protein-coupled receptor G1 gene (ADGRG1, previously known as GPR56). ${ }^{23}$ In the mouse, loss-of-function mutation in Gpr56 mediates the loss of pial basement membrane integrity, resulting in neuronal overmigration and neuronal ectopia. ${ }^{16}$

\section{Conclusions}

In summary, this is the first report of brain ectopia causing trigeminal neuralgia. There was no evidence of vascular co-compression on high-resolution MRI or at the time of surgery. The patient experienced prompt and durable resolution of his facial pain following excision of the small nodular ectopia.

\section{References}

1. Ahmad SM, Garcia F, Sataloff RT: Cerebellopontine angle ganglionic hamartoma: case report. Ear Nose Throat J 89:128-131, 2010

2. Ball RY, Treip CS: Intracranial extracerebral neuroglial hamartoma. Acta Neuropathol 65:172-176, 1984

3. Calzada AP, Go JL, Tschirhart DL, Brackmann DE, Schwartz MS: Cerebellopontine angle and intracanalicular masses mimicking vestibular schwannomas. Otol Neurotol 36:491-497, 2015

4. Costigan M, Moss A, Latremoliere A, Johnston C, VermaGandhu M, Herbert TA, et al: T-cell infiltration and signaling in the adult dorsal spinal cord is a major contributor to neuropathic pain-like hypersensitivity. J Neurosci 29:1441514422, 2009

5. Freeman W: Cortical heterotopia in the pontine meninges. Arch Pathol 2:352-354, 1926

6. Goda M, Isono M, Karashima A, Kasai N, Kobayashi H: Hamartoma in the internal auditory canal. J Clin Neurosci 10:111-113, 2003

7. Gonul E, Yetiser S, Tasar M, Ongoru O: Glioneural hamartoma of the VIIIth nerve. J Laryngol Otol 120:70-73, 2006

8. Han H, Chen G, Zuo H: Microsurgical treatment for 55 patients with hemifacial spasm due to cerebellopontine angle tumors. Neurosurg Rev 33:335-340, 2010

9. Henry MA, Rzasa RS, Beeler JJ, Levinson SR: Caspr reveals an aggregation of nodes and flanking node free zones at the rat trigeminal sensory root and dorsal root entry zones. Glia 49:445-450, 2005

10. Hilton DA, Love S, Gradidge T, Coakham HB: Pathological findings associated with trigeminal neuralgia caused by vascular compression. Neurosurgery 35:299-303, 1994

11. Ho KL: Concurrence of ganglionic hamartoma and heterotopic neuroglial tissue in the cerebellopontine angle. Arch Pathol Lab Med 105:438-439, 1981

12. Isern J, García-García A, Martín AM, Arranz L, MartínPérez D, Torroja C, et al: The neural crest is a source of mesenchymal stem cells with specialized hematopoietic stem cell niche function. eLife 3:e03696, 2014

13. Johnson K, Barragan J, Bashiruddin S, Smith CJ, Tyrrell C, Parsons MJ, et al: Gfap-positive radial glial cells are an essential progenitor population for later-born neurons and glia in the zebrafish spinal cord. Glia 64:1170-1189, 2016

14. Kacker SK, Dasgupta G: Hamartomas of ear and nose. J Laryngol Otol 87:801-805, 1973

15. Lalwani AK: Meningiomas, epidermoids, and other nonacoustic tumors of the cerebellopontine angle. Otolaryngol Clin North Am 25:707-728, 1992

16. Li S, Jin Z, Koirala S, Bu L, Xu L, Hynes RO, et al: GPR56 regulates pial basement membrane integrity and cortical lamination. J Neurosci 28:5817-5826, 2008

17. Love S, Coakham HB: Trigeminal neuralgia: pathology and pathogenesis. Brain 124:2347-2360, 2001

18. Moalem G, Xu K, Yu L: T lymphocytes play a role in neuropathic pain following peripheral nerve injury in rats. Neuroscience 129:767-777, 2004

19. Nishio S, Mizuno J, Barrow DL, Takei Y, O'Brien MS: Intracranial extracerebral glioneural heterotopia. Childs Nerv Syst 4:244-248, 1988

20. Olechowski CJ, Truong JJ, Kerr BJ: Neuropathic pain behaviours in a chronic-relapsing model of experimental autoimmune encephalomyelitis (EAE). Pain 141:156-164, 2009

21. Oya S, Kawahara N, Aoki S, Hayashi N, Shibahara J, Izumi M, et al: Intracranial extracerebral glioneuronal heterotopia. Case report and review of the literature. J Neurosurg 102 (1 Suppl):105-112, 2005

22. Palmer CA, Townsend JJ, Harnsberger HR, Parkin JL, Apfelbaum RI: Cerebellopontine angle glioneuronal hamartoma. Surg Neurol 45:467-469, 1996

23. Piao X, Hill RS, Bodell A, Chang BS, Basel-Vanagaite L, Straussberg R, et al: G protein-coupled receptor-dependent development of human frontal cortex. Science 303:20332036, 2004

24. Rizk HG, Lorenz MB, Friedman R: Neuroglial heterotopia of the internal auditory canal. Otol Neurotol 34:e22-e23, 2013

25. Silverman TA, Enzinger FM: Fibrolipomatous hamartoma of nerve. A clinicopathologic analysis of 26 cases. Am J Surg Pathol 9:7-14, 1985

26. Wolf HK, Buslei R, Schmidt-Kastner R, Schmidt-Kastner PK, Pietsch T, Wiestler OD, et al: NeuN: a useful neuronal marker for diagnostic histopathology. J Histochem Cytochem 44:1167-1171, 1996

\section{Disclosures}

The authors report no conflict of interest concerning the materials or methods used in this study or the findings specified in this paper.

\section{Author Contributions}

Conception and design: Vates. Acquisition of data: Zimering, Stone, Paulzak, Johnson, Vates. Analysis and interpretation of data: Zimering, Johnson, Vates. Drafting the article: Zimering, Johnson. Critically revising the article: Stone, Vates. Reviewed submitted version of manuscript: all authors. Approved the final version of the manuscript on behalf of all authors: Zimering. Study supervision: Vates.

\section{Correspondence}

Jeffrey H. Zimering, Department of Neurosurgery, Mount Sinai Hospital, 1468 Madison Ave., Annenberg Bldg., 8th Fl., New York, NY 10029. email: jeffrey.zimering@mountsinai.org. 